\title{
Enhancement of the Pore Interconnectivity and Porosity of Calcium Phosphate Scaffolds by Acid-Etching Method
}

\author{
Sujeong Lee ${ }^{1} \cdot$ Soyoung Yang $^{1} \cdot$ Indu Bajpai $^{1} \cdot$ Inn-Kyu Kang ${ }^{2} \cdot$ Sukyoung Kim $^{1}$
}

Received: 10 March 2015/Revised: 3 July 2015/Published online: 15 August 2015

(C) The Chinese Society for Metals and Springer-Verlag Berlin Heidelberg 2015

\begin{abstract}
Porous hydroxyapatite (HA)-tricalcium phosphate (TCP) ceramic scaffolds were prepared using a screw-type extrusion method with polymer beads. HA and dicalcium phosphate dehydrates (DCPD) were added at various ratios to obtain different HA/TCP ratios in sintered ceramic scaffolds. To further enhance the pore interconnectivity and porosity, the developed porous ceramic scaffolds were etched with acid solutions. The maximum porosity $(\sim 85 \%)$ was observed in the Ca-P scaffold with the lowest HA $(\sim 7 \%)$ content. On the other hand, the maximum compressive strength was noted in the scaffolds with the highest HA content $(\sim 85 \%)$. X-ray diffraction showed that the extent of the $\beta$-TCP to $\alpha$-TCP phase transformation increased with decreasing HA/DCPD ratio. All HCl-etched scaffolds were observed to generate micropores, which improved the interconnectivity, while biomineralization was found to be the same for both the HCl-etched and nonetched scaffolds. In particular, hydrochloric acid etching is a promising method for improving the interconnectivity and porosity of the ceramic scaffolds.
\end{abstract}

KEY WORDS: Screw-type extrusion; Biomineralization; Porous ceramic scaffolds; HCl etching; Interconnectivity

\section{Introduction}

Synthetic calcium phosphate-based bioceramics has been explored extensively as hard tissue replacements [1]. These materials have been used as a coating on artificial implants, bone cement as well as in bulk form to induce osseointegration [2]. Hydroxyapatite (HA) and tricalcium phosphate (TCP) are widely used Ca-P-based ceramics. When both are used simultaneously, they are known as biphasic

Available online at http://link.springer.com/journal/40195

Sukyoung Kim

sykim@ynu.ac.kr

1 Materials Science and Engineering, Yeungnam University, Gyeongsan-si, Gyeongsangbuk-do 712-749, South Korea

2 Department of Polymer Science and Engineering, Kyungpook National University, Daegu 702-701, South Korea
$(\mathrm{HA}+\beta$ - or $\alpha$-TCP) or triphasic (HA $+\beta$-TCP $+\alpha-\mathrm{TCP})$ bioceramic [3]. The artificial implants must provide a suitable biodegradable property to allow the growth of natural bone. On the other hand, the rate of HA degradation is very slow, whereas that of TCP is too fast. Therefore, a combination of these two phases would provide a better bone substitute than a single phase [4]. Porous scaffolds of bioceramics have been evaluated by many research groups [1]. Porous scaffolds were found to be supportive of cell adhesion, fluid transportation and cell migration. In porous scaffolds, the cell can migrate from one end to another to form a strong bridge among them as well as a strong bond in all directions between the implant and neighboring tissue that would be helpful for rapid healing. The critical pore size required for cell migration was reported to be approximately $100 \mu \mathrm{m}$, and microsized pores $(30 \mu \mathrm{m})$ were found to be useful for fluid transportation in porous scaffolds [1,5].

A variety of methods (gas and surfactant foaming, freeze casting, robocasting, selective laser sintering, 3D 
printing and extrusion type extruder, etc.) have been used to develop porous Ca-P-based scaffolds with an interconnected porous network [6-8]. Wu et al. [9] reported the good in vitro response of 3D-printed $\mathrm{CaSiO}_{3}$ porous scaffolds with good interconnectivity. Ebrahimi et al. [10] reported the polymeric sponge method to prepare the $90 \%$ porous HA/TCP scaffolds having good interconnectivity, but unfortunately, these scaffolds exhibited low compressive strength and modulus. Zhang et al. [11] used a combination of slip casting and polymeric sponge method for producing porous HA scaffolds. On the other hand, Rammay et al. [12] also used the same method to prepare HA/ TCP scaffolds which exhibited comparable mechanical properties to the high-end values of the cancellous bone. Florczyk et al. [13] prepared a porous scaffold of $\beta$-TCP by gel sponge method and found uniform cell spreading and protein release by this porous ceramic scaffold. Sarin et al. [14] reported the preparation method of porous HA/TCP scaffolds using cuttlefish bones treated by several times with chemical and thermal methods, and this method showed the excellent retention of mechanical and microstructural properties. A very limited literature is available on the preparation and the properties of the triphasic porous HA/TCP scaffolds. Ahn et al. [15] presented the properties of $84 \%$ porous triphasic HA/TCP scaffolds prepared by vacuum-assisted foaming method which was observed to show good in vitro bioactivity and compressive strength in acceptable range of human bone. Vani et al. [16] also reported the preparation of triphasic HA/TCP using hydrothermal method and observed good bioactivity of porous HA/TCP scaffolds. As the interconnectivity is essential for fluid transportation in an overall implant, many research groups have reported methods for developing porous scaffolds with in situ interconnected pores (such as salt fusion in a polymer matrix) [17].

In the current work, porous HA/TCP scaffolds were prepared using a screw-type extrusion method. HA was added in pure form, DCPD and $\mathrm{Ca}(\mathrm{OH})_{2}$ were mixed at a $\mathrm{Ca} / \mathrm{P}$ atomic ratio of 1.5 to obtain a TCP phase, and PMMA beads were used to produce a porous structure. TCP formation occurred during sintering, and the content of HA and TCP in the sintered body was analyzed by X-ray diffraction (XRD). The aim of the current study was to enhance the interconnectivity and porosity of the developed porous ceramic implants. To undertake this study,
$\mathrm{HCl}$ acid was chosen as the etching agent, and the porous scaffolds fabricated were etched in different $\mathrm{HCl}$ concentrations for different durations to observe the time-dependent and concentration-dependent effects of acid etching of $\mathrm{Ca}-\mathrm{P}$ scaffolds. The appearance of more micropores in the macropores of the scaffolds indicated the suitability of the approach to enhance interconnectivity without destroying the structure of the scaffolds. A biomineralization test was conducted to observe the adverse effects of $\mathrm{HCl}$ etching. To the best of the authors' knowledge, there are no reports of $\mathrm{HCl}$ acid etching to enhance the porosity and interconnectivity in the developed Ca-P scaffolds.

\section{Materials and Methods}

\subsection{Fabrication of Porous Scaffolds}

Dicalcium phosphate dehydrates (DCPD, $\mathrm{CaHPO}_{4} \cdot 2 \mathrm{H}_{2} \mathrm{O}$ ) were calcined at $600{ }^{\circ} \mathrm{C}$ for $1 \mathrm{~h}$ and then ground in a mortar and pestle. DCPD, hydroxyapatite $\left[\mathrm{HA}, \mathrm{Ca}_{10}(-\right.$ $\left.\mathrm{PO}_{4}\right)_{6}(\mathrm{OH})_{2}$ ] and $\mathrm{Ca}(\mathrm{OH})_{2}$ were then mixed physically by wet ball milling for $24 \mathrm{~h}$ in an ethanol medium. To produce the TCP phase during sintering, the amount of DCPD and $\mathrm{Ca}(\mathrm{OH})_{2}$ was chosen at a $\mathrm{Ca} / \mathrm{P}$ ratio of 1.5 . To make a homogeneous paste, the PMMA beads with a binder and water were added to the above-dried mixture of all three compounds and aged at $25{ }^{\circ} \mathrm{C}$ for 1 day. This paste was used to obtain cylindrical blocks using a screw-type extruder, and the resulting blocks were dried for $24 \mathrm{~h}$ in a (70-30)\% humidity chamber. Finally, the dried samples were sintered at $1250{ }^{\circ} \mathrm{C}$ for $5 \mathrm{~h}$ in a conventional furnace to produce the porous scaffolds. The samples were named according to the mixing ratio of HA and DCPD as listed in Table 1 along with the amount of other materials used in the current work. Figure 1 shows a SEM image of the PMMA beads. The present research group also fabricated water glass-coated HA/TCP porous scaffolds using a similar methodology [18].

\subsection{HCl Acid Etching}

The sintered scaffolds were polished using SiC papers of No. 2000 followed by washing with ethanol in an ultrasonic bath for $20 \mathrm{~min}$. Subsequently, to improve the

Table 1 Sample's nomenclature and composition of raw materials and additives

\begin{tabular}{|c|c|c|c|c|c|c|c|}
\hline Sample & HA/DCPD ratio & HA $(g)$ & DCPD $(g)$ & $\mathrm{Ca}(\mathrm{OH})_{2}(\mathrm{~g})$ & PMMA & $\mathrm{H}_{2} \mathrm{O}$ & Binder \\
\hline H0D100 & $0: 1$ & 0 & 100 & 30.07 & 70 vol $\%$ & 72 vol\% & $22 \mathrm{wt} \%$ \\
\hline H50D100 & $1: 2$ & 50 & 100 & 30.07 & & & \\
\hline H100D100 & $1: 1$ & 100 & 100 & 30.07 & & & \\
\hline H100D50 & $2: 1$ & 200 & 100 & 30.07 & & & \\
\hline
\end{tabular}



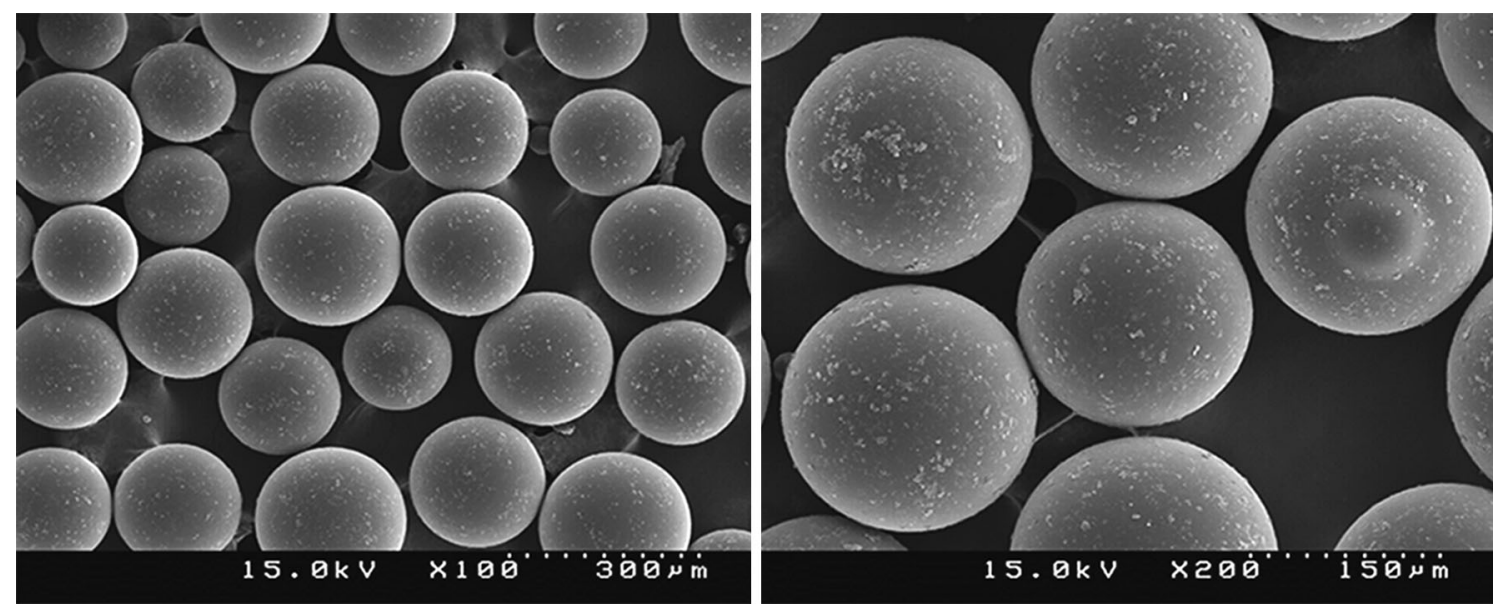

Fig. 1 SEM images of PMMA beads

porosity and pore interconnectivity, the polished scaffolds were treated chemically with $0.1,0.5,1.0$ and $3.0 \mathrm{~mol} / \mathrm{L}$ $\mathrm{HCl}$ for 1, 2, 3 and $4 \mathrm{~min}$ in a shaking incubator at $300 \mathrm{r} /$ $\min$. To remove the residue from the porous scaffolds, the chemically etched scaffolds were washed twice in an ultrasonic bath for $20 \mathrm{~min}$ followed by drying at $60{ }^{\circ} \mathrm{C}$.

\subsection{Microstructural and Phase Analysis}

The surface microstructures of the $\mathrm{HCl}$ - and SBF-treated scaffolds were observed by scanning electron microscopy (SEM, Hitachi, S-4800) at $15 \mathrm{kV}$. Phase analysis of the sintered scaffolds was carried out by XRD (Rigaku) at $40 \mathrm{kV}$ and $30 \mathrm{~mA}$. The HA, $\beta$-TCP and $\alpha$-TCP phases were quantified using the Rietveld method in the X'pert High Score program.

\subsection{Compressive Strength and Porosity Measurement}

For the compression testing, all dry cylindrical scaffolds were cut into pieces, $\sim 4 \mathrm{~mm}$ in diameter and $\sim 8 \mathrm{~mm}$ in height, according to the ISO/DIS 17162 standard. The scaffolds were vertically compressed by up to half of their height using a $4.9-\mathrm{kN}$ load cell with a $0.5-\mathrm{mm} / \mathrm{min}$ crosshead speed on a UTM (Universal Test Machine). The porosity was calculated by the theoretical density and apparent density of the porous scaffolds.

\subsection{Apatite Mineralization}

$1.5 \times \mathrm{SBF}$ (simulated body fluid) with $\mathrm{pH} 7.4$ was prepared by dissolving $\mathrm{NaCl}, \mathrm{NaHCO}_{3}, \mathrm{KCl}, \mathrm{K}_{2} \mathrm{HPO}_{4}, \mathrm{MgCl}_{2}$, $\mathrm{HCl}, \mathrm{CaCl}_{2}$ and Tris buffer in autoclaved MQ water at $37{ }^{\circ} \mathrm{C}$ [19]. SBF was filtered through a $0.2-\mu \mathrm{m}$ filter paper and stored at $4{ }^{\circ} \mathrm{C}$. For the biomineralization activity test, all scaffolds were immersed in $1.5 \times$ SBF for 7 days, and SBF was changed every 3 days. Finally, all samples were washed properly with MQ water to remove the undesired SBF followed by drying in a vacuum for a long time.

\section{Results and Discussion}

Figure 2 presents the surface structure of the sintered porous scaffolds of HA/TCP. Macrosized pores $(\sim 200 \mu \mathrm{m})$ caused by burning out of the PMMA beads were distributed homogenously and interconnected threedimensionally with micropores $(20 \mu \mathrm{m})$. Microsized pores might be created via a solid-state reaction between DCPD and $\mathrm{Ca}(\mathrm{OH})_{2}$. As the sintering behavior of $\mathrm{HA}$ is better than TCP, increasing the amounts of HA resulted in an increase in scaffold shrinkage that resulted in an overall reduction in the porosity of the scaffolds [20].

Figure 3 shows the relative amount of phases (HA, $\beta$ TCP, $\alpha$-TCP) of the HA-DCPD scaffolds sintered at $1250{ }^{\circ} \mathrm{C}$. XRD showed that the extent of the $\beta$-TCP to $\alpha$ TCP phase transformation decreased with increasing amount of HA in the raw materials (refer Table 1). In the case of the H0D100 scaffolds, $7.2 \mathrm{wt} \%$ of HA, $62.9 \mathrm{wt} \%$ of $\beta$-TCP and $29.9 \mathrm{wt} \%$ of $\alpha$-TCP phases were observed as a sintering reaction product of DCPD and $\mathrm{Ca}(\mathrm{OH})_{2}$. In contrast, the sintered H100D50 scaffolds exhibited $\sim 85 \%$ HA and $15 \% \beta$-TCP without a phase transformation to $\alpha$ TCP. Although all HA-DCPD scaffolds were sintered at the same temperature, the $\alpha$-TCP phase transformation was found to be dependent on the initial HA/DCPD ratio. This suggests that the lower HA/DCPD powder ratio in raw materials also stimulated the TCP phase transformation. Interestingly, the HA/TCP ratio in the sintered scaffolds increased linearly with increasing initial amount of HA with the initial $\mathrm{Ca} / \mathrm{P}$ ratio fixed (1.5). The sintered 

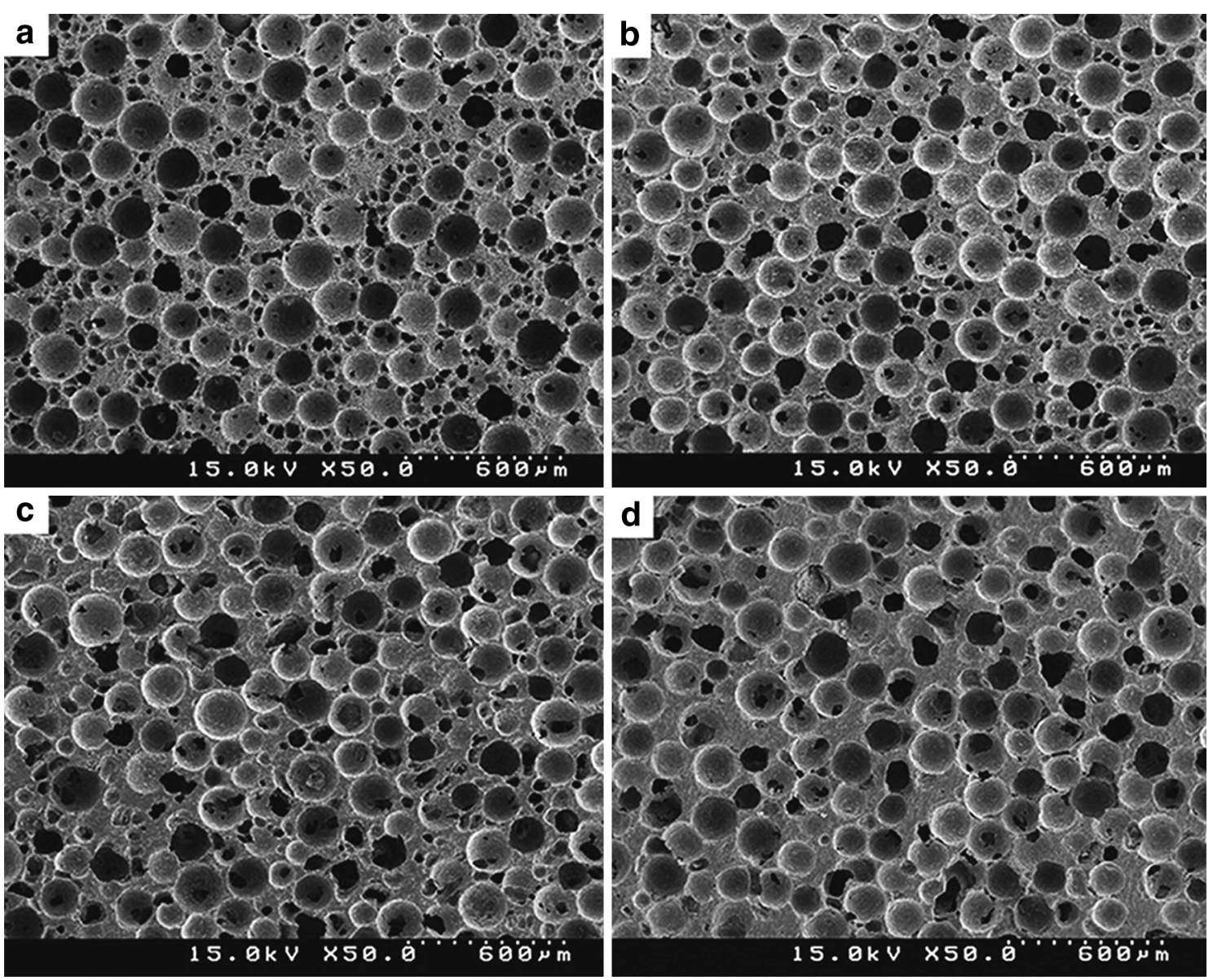

Fig. 2 SEM images of sintered porous blocks: a H0D100; b H50D100; c H100D100; d H100D50

HA100D100 scaffolds exhibited $\sim 60 \%$ HA and $\sim 40 \%$ TCP, which is similar to the HA/TCP ratio (60:40) of natural bone [21].

Figure 4 presents the plots of the compressive strength and porosity of the sintered porous scaffolds. The compressive strength was inversely related to the porosity of the scaffolds. The maximum compressive strength ( 10 MPa) was observed for the H100D50 scaffolds with the lowest porosity $\sim 65 \%$. The compressive strength was found to be related directly to the presence of inherent HA in the scaffolds. In contrast, a higher HA content reduced the overall bulk porosity of the scaffolds. H0D100

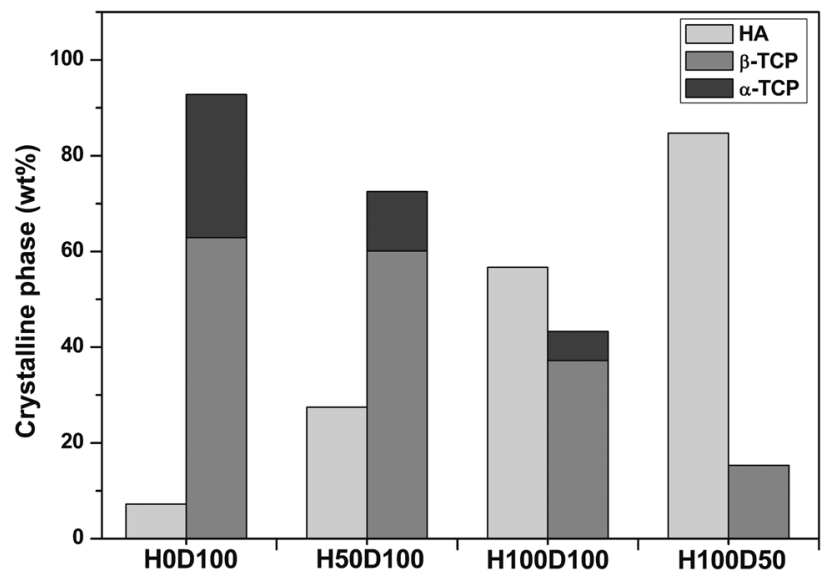

Fig. 3 HA and TCP phase quantification by XRD

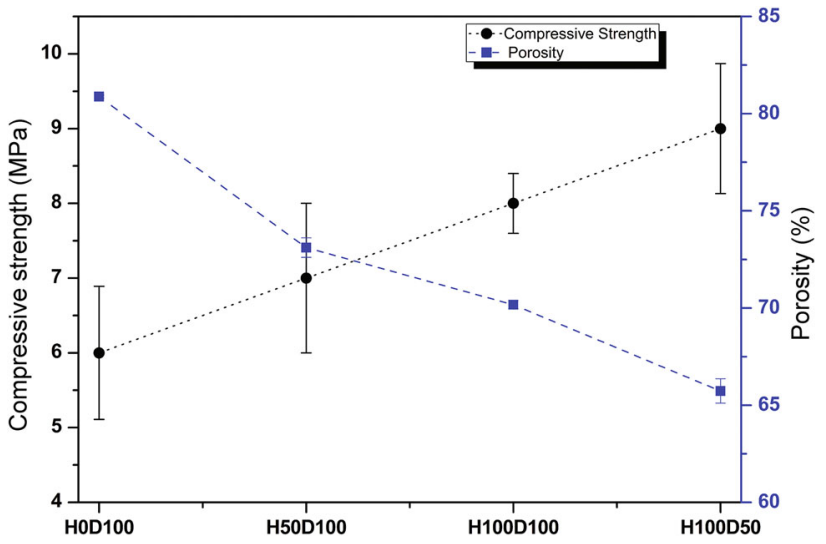

Fig. 4 Compressive strength and porosity of the porous scaffolds 
scaffolds have the maximum porosity, but the lowest compressive strength $(\sim 4.5 \mathrm{MPa})$. The compressive strengths are in the range of $\sim 6.5$ and $\sim 8 \mathrm{MPa}$ in H50D100 and H100D100 scaffolds, which was similar to the range (2-10 MPa) of the cancellous bone [22]. The presence of HA may improve the mechanical strength of TCP matrix, but when the content of HA exceeds a certain limit, it will deteriorate the strength of materials [23, 24]. However, there are a few scientific research publications to be available to compare the compressive strength of the porous triphasic HA/TCP scaffolds. Porosity directly influences the mechanical strength of the scaffolds. Interestingly, the method to prepare porous ceramic scaffolds adopted in the current study showed better results than the results of Ahn et al. [15].

To enhance the interconnectivity, all scaffolds were treated chemically with $0.1,0.5,1.0$ and $3.0 \mathrm{~mol} / \mathrm{L} \mathrm{HCl}$ solutions. In addition, chemical processing was conducted for 1, 2 and $3 \mathrm{~min}$ at each concentration in a shaker at a speed of $300 \mathrm{r} / \mathrm{min}$. After the chemical treatment, the extra acid was removed by washing and centrifugation. Figure 5 shows SEM images of the HCl-etched H100D100 porous scaffolds at various concentrations and durations. Microsized pores created after acid etching and the pore interconnectivity increased with increasing acid concentration and etching time. In addition, the interconnectivity of the macrosized pores was also improved. This means that the $\mathrm{HCl}$ solution penetrated into the porous scaffolds. $3 \mathrm{~mol} / \mathrm{L}$
$\mathrm{HCl}$, however, was an unsuitable concentration because it led to complete collapse of the structure of all samples. In addition, the H0D100 and H50D100 scaffolds etched with $1 \mathrm{~mol} / \mathrm{L} \mathrm{HCl}$ showed a collapsed structure. Therefore, $0.5 \mathrm{~mol} / \mathrm{L} \mathrm{HCl}$ etching for $1 \mathrm{~min}$ might be suitable for the H0D100 and H50D100 scaffolds. On the other hand, $1 \mathrm{~mol} / \mathrm{L} \mathrm{HCl}$ etching for $3 \mathrm{~min}$ is ideal for improving the pore interconnectivity of H100D100 and H100D50. These observations showed that the TCP-based scaffolds could be etched in a short period with very low concentration of $\mathrm{HCl}$ to enhance the appropriate porosity. Based on the results, the chemical reactivity of scaffolds could be related to the HA/TCP ratio, and it can be concluded that the scaffolds with a higher TCP phase were less chemically stable so that it showed a collapsed structure.

Figures 6 and 7 present the graphs of the weight and porosity change according to the etching duration at various $\mathrm{HCl}$ concentrations. The weight of the scaffolds decreased, but the porosity increased with increasing etching duration, which is the indication of the dissolution of materials from the porous scaffolds in the acidic medium. $1 \mathrm{~mol} / \mathrm{L} \mathrm{HCl}$ etching for $3 \mathrm{~min}$ enhanced the porosity of the H100D100 and H100D50 scaffolds by $\sim 15 \%$, without destroying the scaffold structure. Subsequently, a mild $\mathrm{HCl}$ concentration enhanced the porosity significantly in short etching duration. Currently, there is no literature available to compare the enhancement in porosity by acid treatment of the sintered scaffold.

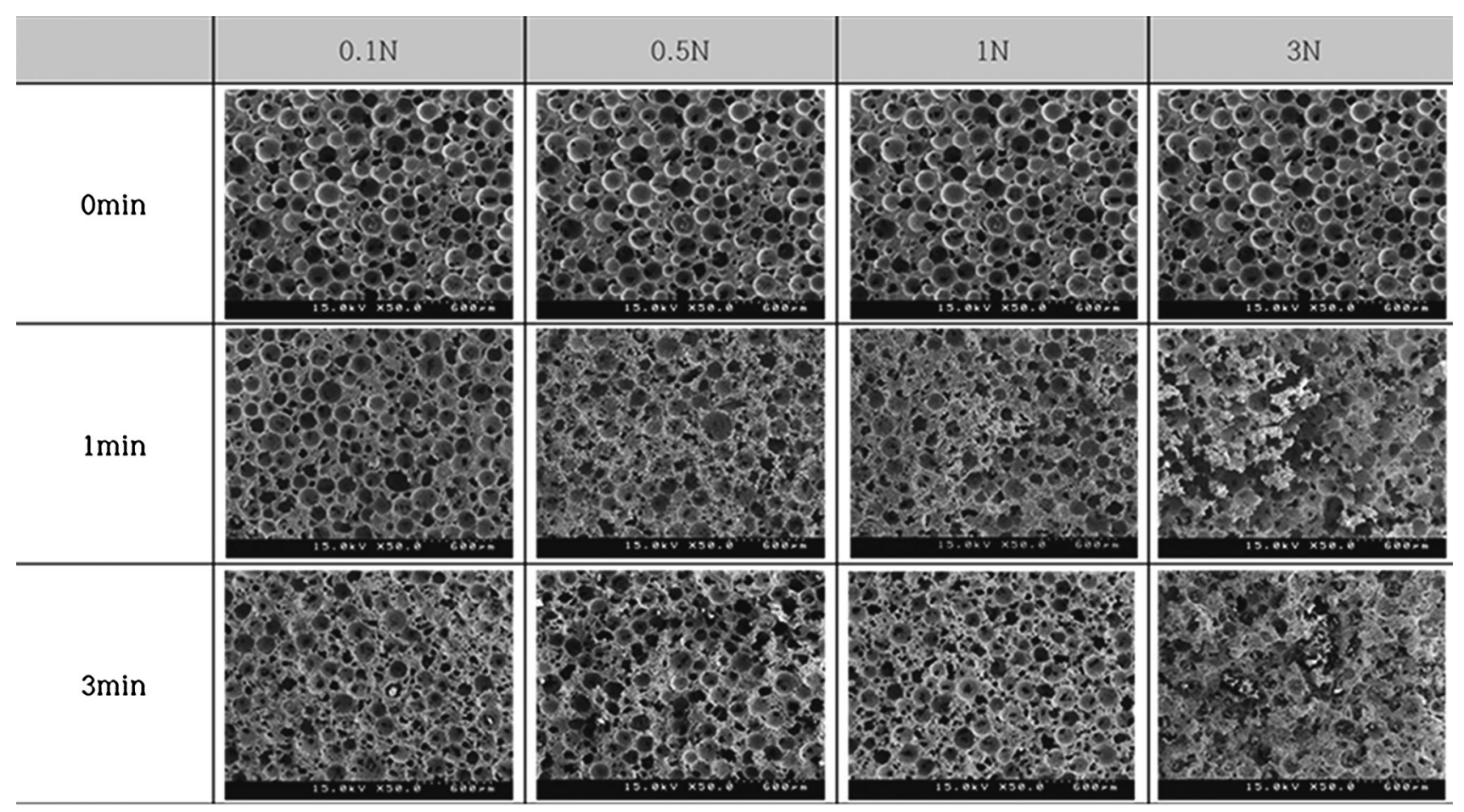

Fig. 5 SEM images of $\mathrm{HCl}$-treated H100D100 porous blocks with various concentrations and durations 

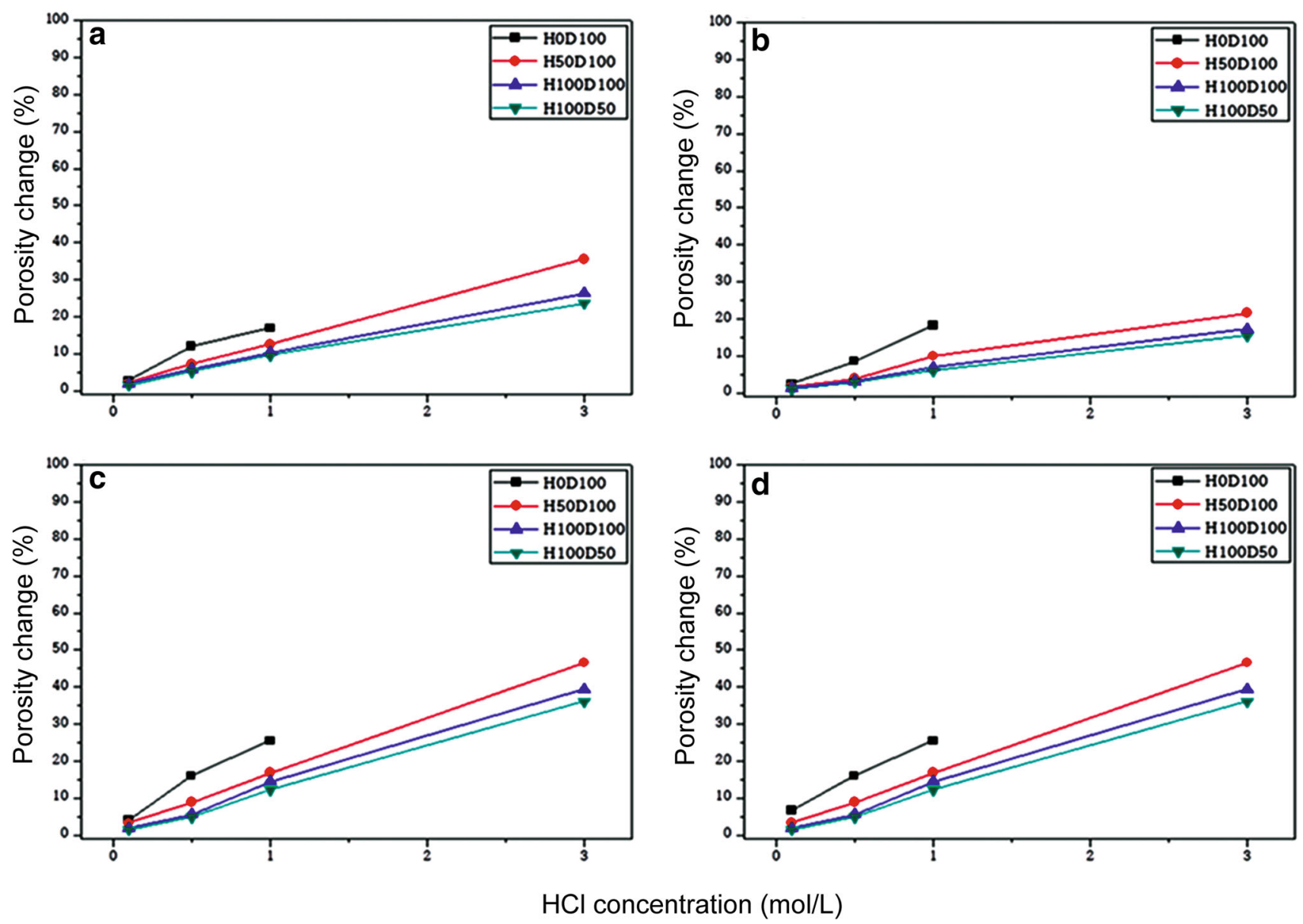

Fig. 6 Comparison of the porosity change of $\mathrm{HCl}$-etched porous blocks with various concentrations and time: a $1 \mathrm{~min}$, b $2 \mathrm{~min}$, c 3 min, d $4 \mathrm{~min}$

To examine the effect of $\mathrm{HCl}$ etching on the biomineralization activity, all scaffolds were treated with the appropriate concentration of $\mathrm{HCl}$, as described above. The samples were properly washed, and sterilized scaffolds were kept in the $1.5 \times \mathrm{SBF}$ for 7 days at $37{ }^{\circ} \mathrm{C}$. Figure 8 shows the results of 7 days SBF test for all scaffolds before and after $\mathrm{HCl}$ etching. Apatite formation was observed in all scaffolds, even in H0D100. Relatively, more biomineralization was observed in the HA-rich scaffolds compared to the H0D100 scaffold, and $\mathrm{HCl}$ etching had no adverse effect on the biomineralization activity of any scaffold. In the current study, bone-like apatite (globular) formation was observed in all the HA/TCP samples, whereas group flake-like apatite was observed in the triphasic HA/TCP samples in a study reported by Ahn et al. [15]. On the other hand, Vani et al. [16] reported the formation of apatite layer on the surface of the porous triphasic HA/TCP scaffold by the hydrothermal method, but the composition of the phases in the final product after sintering was not mentioned in their study. The exact reason behind the different morphologies of the apatite can not be assured at this stage, but the change in composition of HA and $\beta$ - and $\alpha$-TCP might play an important role.

Although the detailed biological experiments were not conducted in this study but according to the available literature based on porous Ca-P scaffolds, it is expected that these porous triphasic HA/TCP will also reveal adequate biological properties. The in vitro and in vivo response of Ca-P-based porous scaffolds has been investigated by many researcher groups and found satisfactorily for the bone tissue applications [25-27]. Nery et al. [28] reported that Ca-P-based scaffolds exhibited good in vivo responses owing to their similar composition to natural bone. Arinzeh et al. [29] reported better in vivo osteogenic responses of (60-70) \% porous HA/TCP scaffolds in the mouse model than the $100 \%$ HA or TCP with the same porosity.

The mode of creating micropores by acid etching without destroying the original structure of the ceramicbased scaffolds might have many applications in the biomedical field. Sohier et al. [30] used $1 \%$ citric acid to etch the $\beta$-TCP macroporous scaffolds ( $\sim 64 \%$ porosity) to generate microporosity for enhancing the protein loading 

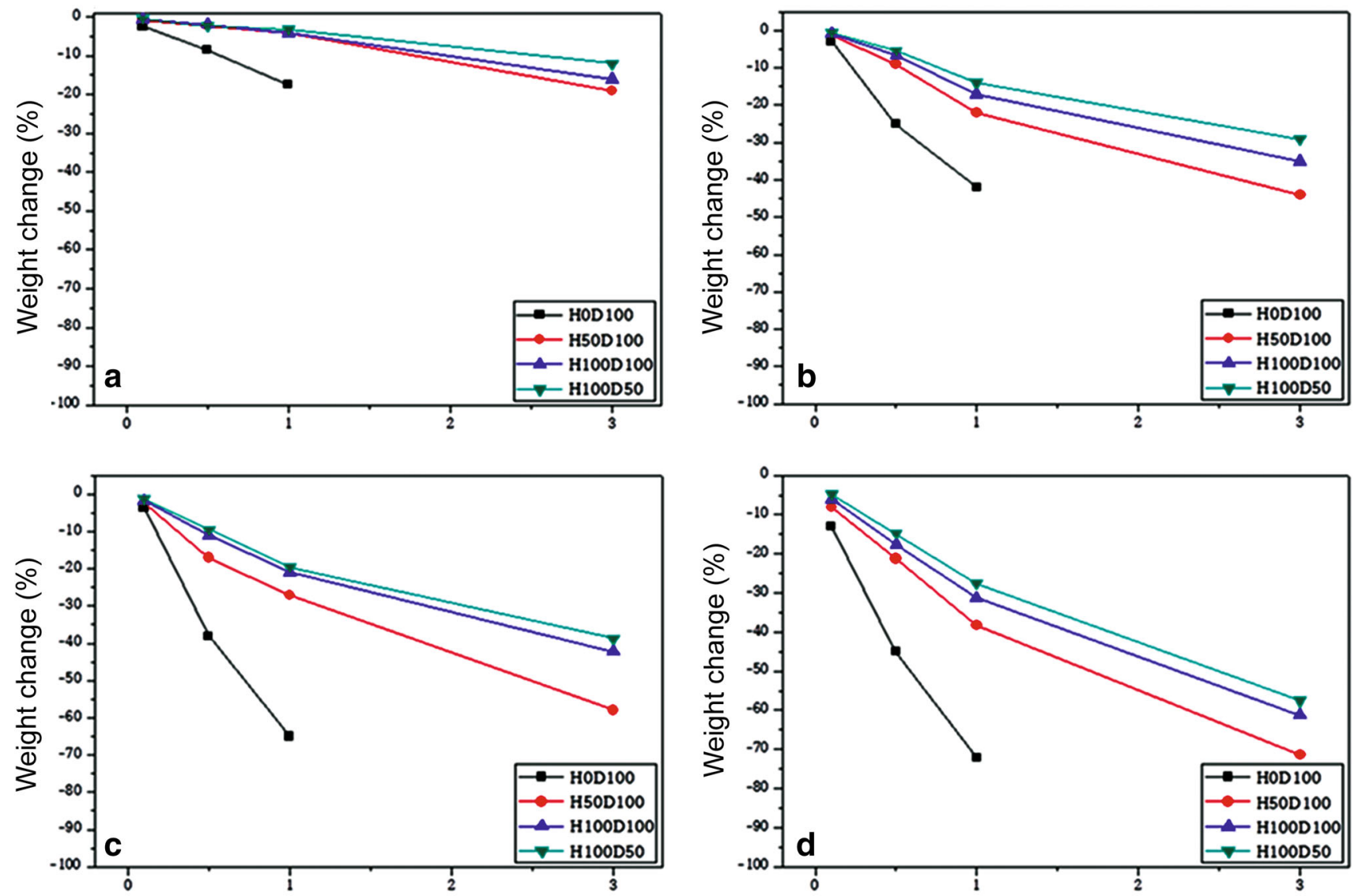

$\mathrm{HCl}$ concentration $(\mathrm{mol} / \mathrm{L})$

Fig. 7 Comparison of the weight change of the HCl-etched porous blocks with various concentrations and duration: a $1 \mathrm{~min}$, b $2 \mathrm{~min}$, c $3 \mathrm{~min}$, d $4 \mathrm{~min}$
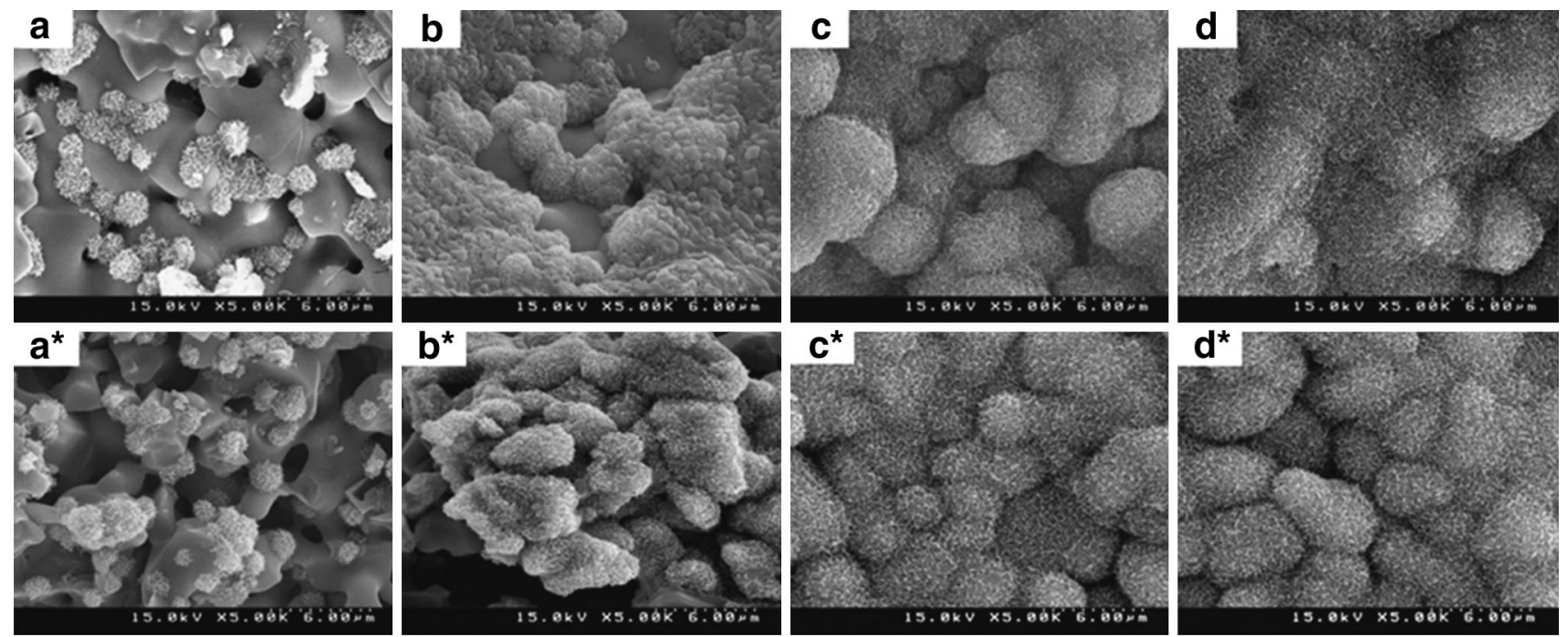

Fig. 8 SEM images of 7-days biomineralization of non-etched a-d and HCl-etched $\mathbf{a}^{*}-\mathbf{d}^{*}$ scaffolds: a H0D100; b H50D100; $\mathbf{c}$ H100D100; d H100D50 
on the scaffold surface. The acid-etching approach adopted in the current work to enhance the interconnectivity is fast, affordable and does not require sophisticated processing facilities.

\section{Conclusions}

Porous HA/TCP scaffolds were fabricated using a screwtype extrusion method. All scaffolds showed homogeneous porosity with macrosized pores $(\sim 200 \mu \mathrm{m})$ along with interconnected micropores $(20 \mu \mathrm{m})$. The porosity decreased with increasing content of inherent HA. The HArich scaffolds, however, exhibited better compressive strength, and the H100D50 scaffolds showed the maximum strength. The poor sintering property of the TCP phase facilitated the fabrication of porous scaffolds, even after sintering at $1250{ }^{\circ} \mathrm{C}$. The pore interconnectivity and the porosity of porous scaffolds were improved by $\mathrm{HCl}$ etching. In particular, H100D100 treated with $1 \mathrm{~mol} / \mathrm{L}$ for $3 \mathrm{~min}$ is suitable for bone substitutes with regard to the dissolution rate and $\mathrm{HA} / \mathrm{TCP}$ ratio. Biomineralization studies of the porous scaffolds showed that it was unaffected by $\mathrm{HCl}$ acid etching. Therefore, the acid-etching method is highly efficient in further enhancing the interconnectivity and porosity of ceramic-based implants in a short etching duration.

Acknowledgments This research was supported by Basic Science Research Program through the National Research Foundation of Korea (NRF) funded by the Ministry of Education, Science and Technology (NRF-2012R1A1A4A01014136).

\section{References}

[1] S.V. Dorozhkin, Acta Biomater. 8, 963 (2012)

[2] G. Daculsi, O. Laboux, O. Malard, P. Weiss, J. Mater. Sci. Mater. Med. 14, 195 (2003)

[3] R.Z.L. Geros, S. Lin, R. Rohanizadeh, D. Mijares, J. Mater. Sci. Mater. Med. 14, 201 (2003)

[4] S.H. Kwon, Y.K. Jun, S.H. Hong, I.S. Lee, H.E. Kim, J. Am. Ceram. Soc. 85, 3129 (2002)
[5] K.A. Hing, S.M. Best, W. Bonfield, J. Mater. Sci. Mater. Med. 10, 135 (1999)

[6] S. Lim, S. Chun, D. Yang, S. Kim, Tissue Eng. Regen. Med. 9, $51(2012)$

[7] J.S. Woyansky, C.E. Scott, W.P. Minnear, Am. Ceram. Soc. Bull. 71, 1674 (1992)

[8] P. Shen, J. Xi, Y. Fu, A. Shaga, C. Sun, Q. Jiang, Acta Metall. Sin. (Engl. Lett.) 27, 944 (2014)

[9] C. Wu, W. Fan, Y. Zhou, Y. Luo, M. Gelinsky, J. Chang, Y. Xia, J. Mater. Chem. 22, 12288 (2012)

[10] M. Ebrahimi, P. Pripatnanont, N. Monmaturapoj, S. Suttapreyasri, J. Biomed. Mater. Res. A 100, 2260 (2012)

[11] Y. Zhang, D. Kong, Y. Yokogawa, X. Feng, Y. Tao, T. Qiu, J. Am. Ceram. Soc. 95, 147 (2012)

[12] H.R.R. Ramay, M. Zhang, Biomaterials 25, 5171 (2004)

[13] S.J. Florczyk, M. Leung, S. Jana, Z. Li, N. Bhattarai, J.I. Huang, R.A. Hopper, M. Zhang, J. Biomed. Mater. Res. A 100A, 3408 (2012)

[14] P. Sarin, S.J. Lee, Z.D. Apostolov, W.M. Kriven, J. Am. Ceram. Soc. 94, 2362 (2011)

[15] M.K. Ahna, Y.W. Moona, Y.H. Koha, H.E. Kim, Ceram. Int. 39, 5879 (2013)

[16] R. Vani, E.K. Girija, K. Elayaraja, S.P. Parthiban, R. Kesavamoorthy, S.N. Kalkura, J. Mater. Sci. Mater. Med. 20, S43 (2009)

[17] W.L. Murphy, R.G. Dennis, J.L. Killeny, D.J. Mooney, Tissue Eng. 8, 43 (2002)

[18] I. Bajpai, S. Yang, I.K. Kang, S. Kim, Adv. Appl. Ceram. (2015). doi:10.1179/1743676115Y.0000000028

[19] H. Oyane, T. Kim, T. Furuya, T. Kokubo, T. Miyazaki, N. Nakamura, J. Biomed. Mater. Res. 65A, 188 (2003)

[20] S. Raynaud, E. Champion, B.D. Assollant, Biomaterials 23, 1073 (2002)

[21] K.A. Hing, Int. J. Appl. Ceram. Technol. 2, 184 (2005)

[22] L.J. Gibson, J. Biomech. 18, 317 (1985)

[23] C. Shuai, Int. J. Appl. Ceram. Technol. 10, 1003 (2013)

[24] C. Shuai, P. Li, J. Liu, S. Peng, Mater. Charact. 77, 23 (2013)

[25] X.J. Sun, L.G. Xia, L.L. Chou, W. Zhong, X.L. Zhang, S.Y. Wang, J. Zhao, X.Q. Jiang, Z.Y. Zhang, Arch. Oral Biol. 55, 195 (2010)

[26] S.K.L. Levengood, S.J. Polak, M.B. Wheeler, A.J. Maki, S.G. Clark, R.D. Jamison, A.J.W. Johnson, Biomaterials 31, 3552 (2010)

[27] S. Bose, M. Roy, A. Bandyopadhyay, Trends Biotechnol. 30, 546 (2012)

[28] E.B. Nery, R.Z. LeGeros, K.L. Lynchet, K. Lee, J. Periodont 63, 729 (1992)

[29] T.L. Arinzeh, T. Tran, J. Mcalary, G. Daculsi, Biomaterials 26, 3631 (2005)

[30] J. Sohier, G. Daculsi, S. Souric, K.D. Groot, P. Layrolle, J. BioMed, Mater. Res. 92A, 1105 (2010) 